\title{
Translation and validation of the Ten-Item Personality Inventory (TIPI) into Bahasa Indonesia
}

\author{
Akhtar, Hanif $\bowtie$ \\ Universitas Gadjah Mada, Indonesia (hanif.akhtar27@gmail.com)
}

\section{䑾}

Received: 20 March 2018

Revised: 3 April 2018

Available Online: 8 May 2018

\section{Abstract}

The need for the very brief measure of the Big Five personality dimensions made the Ten-Item Personality Inventory (TIPI) increasingly popular among researchers around the world. The aim of this study was to investigate the psychometric properties of the TIPI in Indonesia sample (501 participants, $68.1 \%$ of women) by testing the reliability (alpha reliability and test-retest stability) and the construct validity. The items were translated into Indonesian from the original English version. The results of the study showed that the Indonesian version of the TIPI has acceptable psychometric properties with satisfactory levels of test-retest reliability, satisfactory convergent and discriminant construct validity in the relationship with the Big Five Inventory (BFI). However, The TIPI Indonesia has a limitation related to internal structure and internal consistency which is consistent with the properties of the original scale. The TIPI Indonesia is promising scale recommended for research in such conditions: the cost and time are limited, the respondents are fatigue, personality is not the main focus of the research, or in the exploratory study.

Keywords: TIPI; short measure; Big Five; Indonesian adaptation 


\section{Translation and validation of the Ten-Item Personality Inventory (TIPI) into Bahasa Indonesia}

\section{Introduction}

Personality is one of the important areas of psychology that plays an important role in determining individual behavior. One of the most widely used approaches to personality is the trait approach. The Big Five or the Five Factor Model (FFM) is the most widely accepted and used model describing individual personality traits (McCrae, 2009). This model has good evidence to predict various psychological characteristics and has been shown to be relevant in various cultural settings (Goldberg \& Saucier, 1998).

There are many instruments to measure the Big Five personality dimension. The most comprehensive instrument to measure the dimension of Big Five is the Revised NEO Personality Inventory (NEO-PI-R). (Costa $\&$ McCrae, 1992). This instrument consists of 240 items and measures the five factors and each factor consist of 6 subscales. The dimensions that are measured by NEO-PI-R are neuroticism, extraversion, openness, agreeableness, and conscientiousness. Although this instrument has excellent psychometric properties in terms of validity and reliability and also acknowledged as a gold standard for measuring the dimensions of the Big Five, this instrument is too lengthy for research purpose. The inventory takes about 45 minutes to complete. The used of NEO-PI-R also requires permission from the copyright holders. This condition possibly leading to a lack of improvement in the studies of Big Five personality.

Under ideal conditions, researchers have sufficient time and resources to present multi-item tests in order to obtain good validity and reliability. In general, long-term personality scales will have better psychometric properties than short scales (Gosling, Rentfrow, \& Swann, 2003). However, the condition is not always ideal, sometimes researchers are faced with situations where it is irrelevant to use long scales, such as in internet studies, multiple-variable studies, pre-screening studies, and longitudinal studies (Robins, Tracy, Trzesniewski, Potter, \& Gosling, 2001). Therefore, In order to response these conditions, some short instruments measuring the Big Five have been developed.

Some instruments with shorter number of items are 60-item NEO Five Factor Inventory (NEO-FFI) by McCrae and Costa (2004), set of 100 Trait Descriptive Adjectives (TDA) by Goldberg (1992), a compact version of Goldberg's (1992) markers that consist of 40 items by Saucier (1994), the short version of the International Personality Item Pool (Mini-IPIP) that consist of 20 items (Donnellan, Oswald, Baird, \& Lucas, 2006), and the 44-item Big Five Inventory (BFI) by John and Srivastava (1999). Although these instruments are considerably shorter as compared to the NEO-PI-R, it is still needed to develop a briefer instrument to save the time some very specific contexts (Woods \& Hampson, 2005). For example, the study that does not focus on personality but including personality characteristics of participants as a control variable could use the short version of the instrument to save the time and to prevent the boredom of the respondents (Storme, Tavani, \& Myszkowski, 2016). Furthermore, short measures offer several advantages such as allows for shorter time-consuming, cost savings, avoiding respondent's fatigue (Herzberg \& Brähler, 2006) and facilitate the data collection by interviews for respondents with special needs (Joseph, Linley, Harwood, Lewis, \& McCollam, 2004).

Recognizing this need, Gosling et al. (2003) develop a very short Big Five inventory named Ten Item Personality Inventory (TIPI). TIPI is a short instrument measuring the Big-Five dimensions (Extraversion, Agreeableness, Conscientiousness, Emotional Stability, and Openness) consists of ten items, each of them being a pair of adjectives. Participants respond to the items on a 7-point scale, from 1 (strongly disagree) to 7 (strongly agree). The time of responding is very short and does not exceed five minutes (Bąk et al., 2014). According to the study of Gosling et al. (2003), this instrument has an accepted on a wide range of psychometric criteria such as convergent and discriminant validity, test-retest reliability, and external correlates. 
Translation and validation of the Ten-Item Personality Inventory (TIPI) into Bahasa Indonesia

Unlike the selection criteria used by other researchers to create a short version of the scales, Gosling et al. (2003) used the criteria based on optimizing the content validity of TIPI. Gosling et al. (2003) stated the compilation of TIPI by considering the following principles. First, TIPI tried to reach the breadth of the Big Five dimension with a few items. Second, TIPI identified the items that represent both poles of each dimension. Third, where possible the items used were not evaluatively extreme. Fourth, TIPI avoided the use of items that were simply negations. Fifth, TIPI minimized redundancy among descriptors.

The need for the very brief measure of the Big Five personality dimensions made TIPI increasingly popular among researchers around the world. According to Google Scholar, there are more than 4000 citations on the original article introducing the TIPI (Gosling et al., 2003). Numerous studies have attempted make an adaptation of the language and culture of TIPI to various countries, such as in Germany (Muck, Hell, \& Gosling, 2007), Japan (Oshio, Abe, Cutrone, \& Gosling, 2013), Spain (Renau, Oberst, Gosling, Rusiñol, \& Lusar, 2013), South Africa (Metzer, De Bruin, \& Adams, 2014), Croatian (Vorkapić, 2016), Poland (Bąk et al., 2014), Turkey (Atak, 2013), and Italy (Chiorri, Bracco, Piccinno, Modafferi, \& Battini, 2015). Almost all of the studies found that TIPI has a high correlation in each dimension with the Big Five personality scale with more items such as BFI and NEO FFI. Moreover, the existence of short instruments translated into many languages has great potential to integrate research findings in many domains and cultures (Muck et al., 2007).

There is still a debate on the use of a short-form instrument such as TIPI. The study of TIPI from any researchers (Atak, 2013; Ehrhart et al., 2009; Gosling et al., 2003; Muck et al., 2007; Renau et al., 2013; Vorkapić, 2016) mostly found that the reliability coefficients of this instrument did not meet criteria for research instrument that is 0.70 (Nunnally, 1978). However, the TIPI was not designed with these criteria. As mentioned by Gosling et al (2003), it is almost impossible to achieve high levels of alpha coefficients and good fit indices in instruments such as the TIPI with only two items each dimension (with the negative and positive poles). In this condition, the test-retest procedure is recommended to verify the reliability of scales for instruments with a small number of items (Woods \& Hampson, 2005). However, as noted by Gosling et al. (2003), TIPI has an accepted criterion such as convergent and discriminant validity, test-retest reliability, and external correlates. TIPI is very useful in a case where the researchers are willing to tolerate somewhat diminished psychometric properties associated with even briefer measures.

In Indonesia today, there is no short version of Big Five personality scale. The only instrument measuring the Big-Five dimensions using Bahasa Indonesian with the shortest item is Big Five Inventory (BFI) by John and Srivastava (1999) with 44 items. This scale was translated and validated by Ramdhani (2012). The study from Ramdhani (2012) found that the BFI Indonesia has a proper reliability with the alpha coefficients ranged from 0.70 (Extraversion) to 0.79 (Openness). Considering the need for a short-scale measuring Big Five that has reasonable psychometric properties and is useful for practical research needs, it is necessary to develop the short-scale measuring Big Five dimensions in Indonesia. From various studies in various countries, TIPI is worthy of being used for screening individual personalities. In addition, TIPI is a standard and open-source instrument, so that every researcher can use them freely and can be used for cross-cultural studies of personality.

The aim of this study was to provide a validated adaptation of the TIPI in Indonesian samples. This study aim at testing the reliability (alpha reliability and test-retest stability) and the construct validity of the scale. Construct validity was investigated by exploring the factor structure of the TIPI and the convergence between the TIPI and the BFI, which has already been adapted to Bahasa Indonesia by Ramdhani (2012). To test whether the patterns of external correlates of the TIPI matched the patterns of external correlates of the BFI, participants also completed the Satisfaction with Life Scale (SWLS) (Diener, Emmons, Larsen, \& Griffin, 1985) and Positive Affect Negative Affect Schedule (PANAS)(Watson, Clark, \& Tellegen, 1988). The last, I also want to investigate whether the effect of age and gender differences on the Big Five dimensions using TIPI are similar to previously observed with the other instruments (Allemand, Zimprich, \& Hendriks, 2008; Lucas \& Donnellan, 2009; Roberts, Walton, \& Viechtbauer, 2006; Schmitt, Realo, Voracek, \& Allik, 2008; Soto, John, Gosling, \& Potter, 2011). 


\section{Method}

\subsection{Participants}

The participants were native Indonesian students who were attending universities and Senior High School in the province of Yogyakarta, Indonesia. The total of the participants was 501 students. Specifically, $68.1 \%$ of the participants were female $(\mathrm{N}=341)$ and $38.9 \%$ were male $(\mathrm{N}=160)$. The age of the participants ranged between 15 and 40 years old $($ Mean=19.17, $\mathrm{SD}=3.25)$.

\subsection{Materials}

The TIPI Indonesia - TIPI was translated into Bahasa Indonesia using a back-translation methodology. The procedure to adapt TIPI into Bahasa Indonesia following the guide from International Test Commission (2016) and technical consideration from Beaton, Bombardier, Guillemin, and Ferraz (2000). The following step of the adaptation of TIPI into Indonesian were: 1) Two translators who had an educational background in Psychology and had IELTS score minimum of 7.0 translated the TIPI into Bahasa Indonesia independently. 2) Two translators discussed the best translation for each item facilitated by me and generated the semi-final draft of the translation. 3) The semi-final draft of translation was translated back to English by a professional translator who did not know the original version. This last version was compared to the original one and the translators agreed on a final version in Bahasa Indonesia. The Indonesian translation of the TIPI used in this validation study is reported in Table 1.

\section{Table 1}

Original and Indonesian versions of the TIPI

\begin{tabular}{llll}
\hline Item & \multicolumn{1}{c}{ Dimensions } & \multicolumn{1}{c}{ Original item } & \multicolumn{1}{c}{ Indonesian version } \\
\hline 1. & Extroversion & Extraverted, enthusiastic. & Ekstrovert, antusias \\
2. & Agreeableness (reversed) & Critical, quarrelsome. & Suka mengkritik, suka bertengkar \\
3. & Conscientiousness & Dependable, self-disciplined. & Dapat dipercaya, dapat mengendalikan diri \\
4. & Emotional stability (reversed) & Anxious, easily upset. & Cemas, mudah marah \\
5. & Openness & Open to new experiences, complex. & Terbuka pada pengalaman baru, rumit \\
6. & Extroversion (reversed) & Reserved, quiet. & Kalem, pendiam \\
7. & Agreeableness & Sympathetic, warm. & Bersikap simpati, hangat \\
8. & Conscientiousness (reversed) & Disorganized, careless. & Tidak sistematis, kurang berhati-hati \\
9. & Emotional stability & Calm, emotionally stable. & Tenang, stabil secara emosi \\
10 & Openness (reversed) & Conventional, uncreative. & Kuno, kurang kreatif \\
\hline
\end{tabular}

The Big Five Inventory (BFI) - BFI is developed by John and Srivastava (1999) and had already adapted to Bahasa Indonesia by Ramdhani (2012). BFI is the instrument used for estimating the construct validity because TIPI and BFI measured a similar construct. BFI consisted of 44 items, which measured five dimensions of Big Five. The participants were asked to assess themselves on a scale of 1 to 5 . The internal consistency coefficients of the scale reported by Ramdhani (2012) is within the acceptable reliability limits (Openness $=0.79$; Conscientiousness $=0.78$; Extraversion $=0,70 ;$ Agreeableness $=0.76 ;$ Neuroticism $=0.74$ ), while the observed internal consistency in the sample of this research was satisfactory with Cronbach's $\alpha=0.86$ for Extraversion, $\alpha=0.70$ for Agreeableness, $\alpha=0.814$ for Conscientiousness, $\alpha=0.81$ for Neuroticism, and $\alpha=0.71$ for Openness.

The Positive Affect Negative Affect Scale (PANAS) - The PANAS which is developed by Watson, Clark, and Tellegen (1988) was used to assess the Positive Affect and Negative Affect. This scale consists of 20 items. The items include positive and negative adjectives that represent various states of the emotion of the respondents. The participants were asked to indicate how they generally feel on the five-point Likert-type scale ranging from 1 to 5 . The observed internal consistency in the sample of this research was satisfactory with Cronbach's $\alpha=0.87$ for Positive Affect scale and $\alpha=0.85$ for Negative Affect scale.

The Satisfaction with Life Scale (SWLS) - The SWLS which is developed by Diener et al. (1985) was used 
to assess life satisfaction. This scale consists of 5 brief statements that indicate the respondents' general satisfaction with life. The particiants were asked to indicate how they generally feel on the five-point Likert-type scale ranging from 1 to 5 . The observed internal consistency in the sample of this research was satisfactory with Cronbach's $\alpha=0.80$.

\subsection{Procedure}

Data collection - The TIPI Indonesia, BFI, PANAS, and SWLS were applied collectively in classrooms. After I got a permission from the institution to collect the data, I coordinated with the teacher and lecturer to schedule the time of collecting the data in the classroom during class hour. The participants were given brief information about the objective of the research and then the participants who were willing to participate in the research complete the scales. Data confidentiality and anonymity were guaranteed, and students participated voluntarily. The application took approximately 15 minutes. A subsample of 76 students was selected to take the TIPI Indonesia twice in order to investigate the test-retest stability at 3 weeks.

Data analysis - Pearson Product Moment correlation was performed in order to estimaste the convergence between the TIPI and the BFI. Exploratory and confirmatory factor analyses were performed for structural validity. Two approaches of reliabilities were tested, those are internal consistency coefficient (alpha) and test-retest method. IBM SPSS 23 was used to compute Pearson product-moment correlations, exploratory factor analyses, and internal consistency coefficient (alpha), while Amos 23 was used to conduct the confirmatory factor analyses.

\section{Result}

\subsection{Descriptive statistics, age and gender differences}

Descriptive statistics and correlates among the dimensions of the TIPI Indonesia is reported in Table 2.

\section{Table 2}

Descriptive statistics and intercorrelates of the dimensions of the TIPI Indonesia

\begin{tabular}{|c|c|c|c|c|c|c|c|c|}
\hline Dimensions & $N$ & Mean & $S D$ & Age & A & $\mathrm{C}$ & ES & $\mathrm{O}$ \\
\hline Extraversion & 501 & 8.42 & 2.800 & -0.028 & $-0.131^{* *}$ & 0.066 & 0.012 & $0.215^{* *}$ \\
\hline Agreeableness & 501 & 10.06 & 1.974 & $0.144 * *$ & & $0.284^{* *}$ & $0.361^{* *}$ & $0.125^{* *}$ \\
\hline Conscientiousness & 501 & 9.24 & 1.974 & $0.098 *$ & & & $0.311^{* *}$ & $0.161^{* *}$ \\
\hline Emotional_Stability & 501 & 8.85 & 2.392 & $0.115^{* *}$ & & & & $0.111^{*}$ \\
\hline Openness & 501 & 10.11 & 1.938 & 0.048 & & & & \\
\hline
\end{tabular}

The effect of age and gender differences on the five total scores of each dimension was investigated. There was a significant positive correlations between age and agreeableness $(\mathrm{r}=0,144 p<.01)$, conscientiousness $(\mathrm{r}=$ $0.098, p<.05)$, and emotional stability $(\mathrm{r}=0.115, p<.01)$. Regarding the effect of gender, I found that women scored significantly higher than men on extraversion $(\mathrm{t}=2.19, p<.05)$, while men scored significantly higher than women on emotional stability $(\mathrm{t}=-2.71, p<.01)$.

\subsection{Reliability Analyses}

Reliability of the scale was analyzed with Cronbach alpha and test-retest consistency. The Cronbach alpha reliability coefficient of the scale was found to be 0.71 for Extraversion, 0.31 for Agreeableness, 0.30 for Conscientiousness, 0.65 for Emotional Stability, and 0.34 for Openness. These reliability coefficients were quite low for the instrument for research, but this finding is not far from Gosling and colleague's finding on their study on the original TIPI. Gosling suggested that if reliability estimates are needed, a more appropriate index would be test-retest reliability. The test-retest reliability of the scale was applied to 76 participants with an interval of 3 
Akhtar, H.

weeks. The test-retest reliability coefficient of the scale obtained was found to be 0.85 for Extraversion, 0.79 for Agreeableness, 0.71 for Conscientiousness, 0.74 for Emotional Stability, and 0.75 for Openness. All of the scales had test-retest reliability coefficient above 0.70 and met criteria for research instrument that is 0.70 (Nunnally, 1978). The analysis result of the reliability of the scale was shown in Table 3.

Table 3

Reliability of the original and Indonesian version of TIPI

\begin{tabular}{lcccc}
\hline \multicolumn{1}{c}{ Dimension } & $\begin{array}{c}\text { Cronbach's } \alpha \text { of } \\
\text { Original Version }\end{array}$ & $\begin{array}{c}\text { Cronbach's } \alpha \text { of } \\
\text { Indonesian Version }\end{array}$ & $\begin{array}{c}\text { Inter-item } \\
\text { correlation }\end{array}$ & $\begin{array}{c}\text { Test-retest } \\
(3 \text { weeks })\end{array}$ \\
\hline Extraversion & 0.68 & 0.71 & 0.55 & 0.85 \\
Agreeableness & 0.40 & 0.31 & 0.20 & 0.79 \\
Conscientiousness & 0.50 & 0.30 & 0.18 & 0.71 \\
Emotional Stability & 0.73 & 0.65 & 0.49 & 0.74 \\
Openness & 0.45 & 0.34 & 0.21 & 0.75 \\
\hline
\end{tabular}

\subsection{Validity analysis}

Exploratory Factor Analysis (EFA) - To verify whether the sample was appropriate to the factor analysis, the Kaiser-Meyer-Olkin (KMO) and Bartlett's sphericity test were used. The KMO was 0.606, which indicates the data was sufficiently adequate for the factor analysis and Bartlett's sphericity test was significant $\left(p<.01, \chi^{2}\right.$ $=828.486$ ), showing there were sufficient correlations among the variables for factor analysis use. The extraction of factors was conducted through analyzing the principal components and varimax rotation. The determined five-factor solution has explained $74.38 \%$ of the total variance. The rotation matrix's factor loads are presented in Table 4. As it showed in table 4, generally loadings factor of the items are not so high, and they are not structured as it was expected.

Table 4

Factor solution of the TIPI Indonesia's items

\begin{tabular}{cccccc}
\hline \multirow{2}{*}{ Item } & \multicolumn{5}{c}{ Factor } \\
\cline { 2 - 6 } & 1 & 2 & 3 & 4 & 5 \\
\hline TE1 & 0.280 & $\mathbf{0 . 8 3 5}$ & 0.040 & -0.036 & 0.074 \\
TA2 & $\mathbf{- 0 . 0 3 6}$ & -0.388 & 0.548 & 0.227 & 0.322 \\
TC3 & 0.703 & 0.115 & 0.183 & $\mathbf{0 . 2 0 1}$ & -0.124 \\
TES4 & 0.052 & 0.080 & $\mathbf{0 . 8 8 4}$ & 0.041 & 0.112 \\
TO5 & 0.652 & 0.069 & -0.153 & -0.397 & $\mathbf{0 . 3 4 1}$ \\
TE6 & -0.191 & $\mathbf{0 . 8 6 4}$ & -0.034 & 0.049 & 0.129 \\
TA7 & $\mathbf{0 . 6 8 3}$ & -0.062 & 0.133 & 0.134 & 0.160 \\
TC8 & 0.170 & 0.008 & 0.059 & $\mathbf{0 . 9 0 9}$ & 0.092 \\
TES9 & 0.445 & 0.007 & $\mathbf{0 . 6 9 0}$ & -0.016 & -0.236 \\
TO10 & 0.115 & 0.166 & 0.074 & 0.068 & $\mathbf{0 . 8 5 7}$ \\
\hline
\end{tabular}

Confirmatory Factor Analysis (CFA) - Although it is not recommended to conduct CFA with less than three indicators per latent variable (Kline, 2005), the factor structure of the TIPI Indonesia was investigated in order to provide additional evidence for the construct validity of the TIPI Indonesia. The structural model was tested using the maximum likelihood estimation in the AMOS 23. In the model, the variance and the largest factor loading of each latent variable were set to. Two statistical indices were used to evaluate the model fit: Goodness of Fit Index (GFI) > 0.90, and Root Mean Square Error of Approximation (RMSEA) < 0.08 (Hu \& Bentler, 1999; Schumacker \& Lomax, 2010).

The initial model did not fit well to the data $(\chi 2 / \mathrm{df}=249,374 / 30$, GFI $=0.906$, RMSEA $=0.121)$. I then looked for errors covariance to be estimated using modification indices, as Muck et al. (2007) suggested when working on the TIPI-G. Modification indices suggested to freely estimate six error covariances: Item 1 with items 7, item 6 with item 9 and 5, item 2 with item 4, item 8 with item 5, item 4 with item 10. After correlating 
Translation and validation of the Ten-Item Personality Inventory (TIPI) into Bahasa Indonesia errors, the model fit well to the data $(\chi 2 / \mathrm{df}=72,484 / 24$, GFI $=0.972, \mathrm{RMSEA}=0.064)$. The standardized factor loadings in the modified model were 0.75 and 0.71 for Extraversion, 0.65 and 0.73 for Emotional Stability, 0.39 and 0.61 for Agreeableness, 0.51 and 0.38 for Conscientiousness, and 0.50 and 0.44 for Openness.

Convergence across measures - I correlated the BFI scale scores with the TIPI Indonesia scale scores. The convergent validities, shown in the diagonal of Table 5.

\section{Table 5}

Convergent correlations between TIPI Indonesia and BFI

\begin{tabular}{lccccc}
\hline & \multicolumn{5}{c}{ BFI } \\
\cline { 2 - 6 } & $\mathrm{E}$ & $\mathrm{A}$ & $\mathrm{C}$ & $\mathrm{ES}$ & $\mathrm{O}$ \\
\hline TIPI & $0.799^{* *}$ & $0.124^{* *}$ & 0.087 & $0.225^{* *}$ & -0.080 \\
Extraversion & & $0.608^{* *}$ & $0.249^{* *}$ & $0.124^{* *}$ & 0.049 \\
Agreeableness & & & $0.664^{* *}$ & $0.256^{* *}$ & -0.035 \\
Conscientiousness & & & & $0.683^{* *}$ & 0.053 \\
Emotional Stability & & & & & $0.478^{* *}$ \\
Openness & & & &
\end{tabular}

As can be seen, correlations between the items of the same dimensions were significant and higher than correlations between items of different dimensions. The correlations between the two measures of the same dimensions of the BFI were: 0.799 for Extraversion, 0.608 for Agreeableness, 0.664 for Conscientiousness, 0.683 for Emotional Stability, and 0.478 for Openness (all significant at $p<.05$ ). The convergent correlations mean was $r=0.646$, while discriminant correlations ranged from 0.035 to 0.256 ( mean $r=0.128$ ). These convergent correlations were far exceeded the discriminant correlations. These results provide evidence for the convergent validity of the TIPI measure.

External correlates - To test whether the patterns of external correlates of the TIPI matched the patterns of external correlates of the BFI, I correlated both instruments with each of the other constructs, such as Positive Affect, Negative Affect, and Life satisfaction. These patterns of external correlates are shown separately for each of the Big-Five dimensions in Table 6.

\section{Table 6}

External correlates of the TIPI and BFI

\begin{tabular}{lllllllllll}
\hline \multirow{2}{*}{ Criterion Measure } & \multicolumn{2}{c}{ Extraversion } & \multicolumn{2}{c}{ Agreeableness } & \multicolumn{2}{c}{ Conscientiousness } & \multicolumn{2}{c}{ Emotional Stability } & \multicolumn{2}{c}{ Openness } \\
\cline { 2 - 11 } & TIPI & BFI & \multicolumn{1}{c}{ TIPI } & BFI & TIPI & BFI & TIPI & BFI & TIPI & BFI \\
\hline Life satisfaction & 0.141 & 0.243 & 0.262 & 0.363 & 0.226 & 0.291 & 0.329 & 0.318 & 0.107 & 0.015 \\
Positive Affect & $0.341^{*}$ & $0.472^{*}$ & $0.168^{*}$ & $0.287^{*}$ & $0.268^{*}$ & $0.421^{*}$ & 0.251 & 0.327 & $0.377^{*}$ & $0.224^{*}$ \\
Negative Affect & -0.173 & -0.248 & $-0.259^{*}$ & $-0.379^{*}$ & -0.281 & -0.302 & -0.589 & -0.647 & $-0.168^{*}$ & $-0.001^{*}$ \\
\hline
\end{tabular}

Note. ${ }^{*} \mathrm{z}$ score between TIPI and BFI differ significantly from each other at the .05 level.

To test the significance of the difference between two correlation coefficients, I used the Fisher r-to-z transformation. The way to do this is by transforming the correlation coefficient values or $r$ values, into $z$ scores, so that the $\mathrm{z}$ scores can be compared and analyzed for statistical significance by determining the observed $\mathrm{z}$ test statistic. To do this computation, I used the online calculator from http://vassarstats.net/rdiff.html. From this computation, I found that 6 of 15 correlation coefficients differ significantly. Mostly, the correlation coefficients of TIPI and BFI with external variables were equal. I also computed the correlation between the two columns of a transformed r-to-z score. The TIPI displayed patterns of correlations that were identical to the BFI; column-vector correlations ranged from 0.90 for Openness to 0.99 for Extraversion. Overall, the TIPI had patterns of correlations that matched closely with BFI. However, because the TIPI had lower internal consistency coefficients than the BFI, the absolute magnitude of the correlations also weaker. 


\section{Discussion}

This study aimed to provide a validated adaptation of the TIPI in Indonesian samples. In my process, I also compared my finding to those of the original version (Gosling et al., 2003). The TIPI Indonesia showed satisfactory test-retest reliability and convergent validity with the BFI. The TIPI Indonesia also displayed patterns of correlations that were identical to the BFI, although the magnitude of the correlations was weaker than the BFI. This finding was similar Gosling and his colleagues finding in the validation study of the original version of TIPI.

The gender differences found in the TIPI are as might be expected based on previous research (Roberts et al., 2006; Schmitt et al., 2008). Generally, women tend to score lower in Emotional Stability. Trends for the other traits were also in the same direction as in previous literature. The correlation between Big Five dimensions and age using TIPI also found similar with previous research (Allemand et al., 2008; Lucas \& Donnellan, 2009; Soto et al., 2011) that Agreeableness and Conscientiousness were positively associated with age. Furthermore, observed relationships with Life satisfaction, Positive Affect, and Negative Affect were consistent with those observed with longer questionnaires assessing the Big Five dimensions of personality (Donnellan et al., 2006; González Gutiérrez, Jiménez, Hernández, \& Puente, 2005; Steel, Schmidt, \& Shultz, 2008; Tanksale, 2015).

Gosling et al. (2003) only examined the criterion-related validity and convergent validity for the validity study. However, exploratory and confirmatory factor analysis were not performed for the validity of factor structure of the original scale. In this study, I have investigated the factor structure of the TIPI by using exploratory and confirmatory factor analysis. The result of exploratory factor analysis is still not satisfactory. Some items' loadings are not so high, and the grouping of the items are not structured as it was expected. The initial model of confirmatory factor analysis also did not fit with the data. The factor structure needed to be adjusted by including some error covariances which is also consistent with previous findings from Muck et al (2007) This finding was not a surprise, as mentioned by Gosling et al. (2003) that it almost impossible to achieve good fit indices in factor alaysis in instruments such as the TIPI with only two items each dimension.

The main limitations of The TIPI Indonesia are related to the quality of its internal consistency on several of the dimensions of the TIPI. This finding is similar with the psychometric properties of the original scale and its adaptations to other languages (Bąk et al., 2014; Gosling et al., 2003; Hofmans, Kuppens, \& Allik, 2008; Muck et al., 2007; Storme et al., 2016). Regarding to this issue, Gosling et al. (2003) noted that the TIPI was not designed to meet high standards of reliability or other psychometric properties with high alphas and good CFA fits. The goal of the TIPI was to develop a very brief instrument that optimized validity. Criteria like alpha and factor structures are only meaningful to the extent they reflect improved validity. Moreover, some researchers have argued that alphas are misleading when using scales that include few items (Kline, 2000; Woods \& Hampson, 2005).

There were two possibilities that the internal consistency of the TIPI was low. First, it was related to the translation from English to Bahasa Indonesian. For example, we translate conventional as kuno. The word kuno had a negative meaning in Indonesian and people tend to give a low score on this item, but unfortunately, we could not find the best translation for this word. Another possibility is that the respondents confused with the format of the item. It is reflected from the comment from participants. They had difficulties to evaluate two adjectives simultaneously. This is in line with the guideline from Aiken (1999), which propose that a good item contains only one statement and avoids multiple judgments. In the future study, it is better to verify the comprehension of the participants concerning the adjective used to determine whether item format of the two-adjective structure confused them or not.

There is a contradictory regarding the quality of TIPI Indonesia. The TIPI has a limitation related to internal structure and internal consistency (Cronbach's alpha). However, as noted by Gosling et al. (2003), studies based on external criteria should be a priority. The evidence of validity should be based on relationships established 
with external variables. Regarding to this external criteria, the TIPI Indonesia has met the criteria. One important question to consider is, when will we choose to use TIPI Indonesia as an instrument measuring Big Five personality factors? Considering several limitations of TIPI, obviously, the TIPI Indonesia is not an appropriate instrument when comprehensive assessments of personality are required (e.g., for diagnostic purposes). Due to the relatively low internal consistency, measuring traits using a short scale such TIPI may also lead to the underestimation of the role of personality traits (Credé, Harms, Niehorster, \& Gaye-Valentine, 2012)

So, what are the benefits of the TIPI Indonesia? With only 10 items, TIPI Indonesia incurs very little fatigue or other costs on participants, and it saves a lot of time. The TIPI Indonesia could even be applied in interview survey. As stated by Storme et al (2016) regarding the use of French TIPI, TIPI Indonesia may also be a useful measure of the Big Five dimensions of personality when personality is not the main focus of the study and for exploratory purposes only. Personality research and empirical studies can benefit from being able to control for the Big Five dimensions. However, if the focus of the study is about personality, I suggest the researchers use more robust measures, such as the Indonesian versions of the BFI (Ramdhani, 2012) which have better internal structures.

\section{Conclusion}

The results of this study provide some support to the convergent validity and test-retest reliability of the TIPI Indonesia. However, there is a limitation of this scale related to internal structure and Cronbach's alpha. Based on the finding, I recommend using TIPI only in the limited time and in the research that personality is not the main focus of the study. Moreover, because Indonesia is a wide country and consists of thousands of islands, further study is needed to test TIPI Indonesia to a larger sample from various regions in Indonesia.

Acknowledgements: Acknowledgment is directed to the Indonesian Endowment Fund for Education (LPDP) of Ministry of Finance of the Republic of Indonesia who supported this research.

\section{References}

Aiken, L. R. (1999). Personality assessment methods and practice (3rd rev. ed.). Ashland, OH, US: Hogrefe \& Huber Publishers.

Allemand, M., Zimprich, D., \& Hendriks, A. A. J. (2008). Age differences in five personality domains across the life span. Developmental Psychology, 44(3), 758-770. https://doi.org/10.1037/0012-1649.44.3.758

Atak, H. (2013). Adaptation of the on-papers of the personality scale to Turkish culture [On-Maddeli Kişilik Ölçeği'nin Türk Kültürü’ne Uyarlanması]. Nöro Psikiyatri Arşivi, 50(4), 312-319. https://doi.org/10.4274/npa.y6128

Bąk, W., Mielniczuk, E., Oleś, P. K., Purc, E., Laguna, M., \& et al. (2014). Short measure of personality TIPI-P in a Polish sample. Roczniki Psychologiczne, 17(2)), 421-437.

Beaton, D. E., Bombardier, C., Guillemin, F., \& Ferraz, M. B. (2000). Guidelines for the process of cross-cultural adaptation of self-report measures. Spine, 25(24), 3186-3191.

Chiorri, C., Bracco, F., Piccinno, T., Modafferi, C., \& Battini, V. (2015). Psychometric properties of a revised version of the ten item personality inventory. European Journal of Psychological Assessment, 31(2), 109-119. https://doi.org/10.1027/1015-5759/a000215

Costa, P. T. J., \& McCrae, R. . (1992). Revised NEO personality inventory and NEO five-factor inventory professional manual. Odessa, FL: Psychological Assessment Resources.

Credé, M., Harms, P., Niehorster, S., \& Gaye-Valentine, A. (2012). An evaluation of the consequences of using short measures of the Big Five personality traits. Journal of Personality and Social Psychology, 102(4), 874-888. https://doi.org/10.1037/a0027403

Diener, E. D., Emmons, R. A., Larsen, R. J., \& Griffin, S. (1985). The satisfaction with life scale. Journal of Personality Assessment, 49(1), 71-75. 
Akhtar, H.

Donnellan, M. B., Oswald, F. L., Baird, B. M., \& Lucas, R. E. (2006). The Mini-IPIP Scales: Tiny-yet-effective measures of the Big Five Factors of Personality. Psychological Assessment, 18(2), 192-203. https://doi.org/10.1037/1040-3590.18.2.192

Ehrhart, M. G., Ehrhart, K. H., Roesch, S. C., Chung-Herrera, B. G., Nadler, K., \& Bradshaw, K. (2009). Testing the latent factor structure and construct validity of the Ten-Item Personality Inventory. Personality and Individual Differences, 47(8), 900-905. https://doi.org/10.1016/j.paid.2009.07.012

Goldberg, L. R. (1992). The development of markers for the Big-Five factor structure. Psychological Assessment, 4(1), 26.

Goldberg, L. R., \& Saucier, G. (1998). What is beyond the Big Five? Journal of Personality, 66(4), $495-524$.

González Gutiérrez, J. L., Jiménez, B. M., Hernández, E. G., \& Puente, C. P. (2005). Personality and subjective well-being: big five correlates and demographic variables. Personality and Individual Differences, 38(7), 1561-1569. https://doi.org/10.1016/j.paid.2004.09.015

Gosling, S. D., Rentfrow, P. J., \& Swann, W. B. (2003). A very brief measure of the Big-Five personality domains. Journal of Research in Personality, 37(6), 504-528. https://doi.org/10.1016/S0092-6566(03)00046-1

Herzberg, P. Y., \& Brähler, E. (2006). Assessing the big-five personality domains via short forms. European Journal of Psychological Assessment, 22(3), 139-148. https://doi.org/10.1027/1015-5759.22.3.139

Hofmans, J., Kuppens, P., \& Allik, J. (2008). Is short in length short in content? An examination of the domain representation of the Ten Item Personality Inventory scales in Dutch language. Personality and Individual Differences, 45(8), 750-755. https://doi.org/10.1016/j.paid.2008.08.004

Hu, L., \& Bentler, P. M. (1999). Cutoff criteria for fit indexes in covariance structure analysis: Conventional criteria versus new alternatives. Structural Equation Modeling: A Multidisciplinary Journal, 6(1), 1-55. https://doi.org/10.1080/10705519909540118

International Test Commission. (2016). The ITC guidelines for translating and adapting tests (2nd ed.). Retrieved from https://www.InTestCom.org

John, O. P., \& Srivastava, S. (1999). The Big Five trait taxonomy: History, measurement, and theoretical perspectives. Handbook of Personality: Theory and Research, 2(1999), 102-138.

Joseph, S., Linley, P. A., Harwood, J., Lewis, C. A., \& McCollam, P. (2004). Rapid assessment of well-being: The Short Depression-Happiness Scale (SDHS). Psychology and Psychotherapy: Theory, Research and Practice, 77(4), 463-478.

Kline, P. (2000). Handbook of psychological testing. London: Routledge.

Lucas, R. E., \& Donnellan, M. B. (2009). Age differences in personality: Evidence from a nationally representative Australian sample. Developmental Psychology, 45(5), 1353-1363. https://doi.org/10.1037/a0013914

McCrae, R. R. (2009). Personality profiles of cultures: Patterns of ethos. European Journal of Personality, 23(3), 205-227. https://doi.org/10.1002/per.712

McCrae, R. R., \& Costa, P. T. (2004). A contemplated revision of the NEO Five-Factor Inventory. Personality and Individual Differences, 36(3), 587-596. https://doi.org/10.1016/S0191-8869(03)00118-1

Metzer, S. A., De Bruin, G. P., \& Adams, B. G. (2014). Examining the construct validity of the Basic Traits Inventory and the Ten-Item Personality Inventory in the South African context: original research. $S A$ Journal of Industrial Psychology, 40(1), 1-9.

Muck, P. M., Hell, B., \& Gosling, S. D. (2007). Construct validation of a short five-factor model instrument. European Journal of Psychological Assessment, 23(3), 166-175.

https://doi.org/10.1027/1015-5759.23.3.166

Nunnally, J. . (1978). Psychometric theory (2nd ed.). New York: McGraw-Hill.

Oshio, A., Abe, S., Cutrone, P., \& Gosling, S. D. (2013). Big Five Content Representation of the Japanese Version of the Ten-Item Personality Inventory. Psychology, 04(12), 924-929. https://doi.org/10.4236/psych.2013.412133

Ramdhani, N. (2012). Language and culture adaptation of the Big Five personality scale [Adaptasi Bahasa dan Budaya dari Skala Kepribadian Big Five]. Jurnal Psikologi, 39(2), 189-205. 
Translation and validation of the Ten-Item Personality Inventory (TIPI) into Bahasa Indonesia

Renau, V., Oberst, U., Gosling, S. D., Rusiñol, J., \& Lusar, A. C. (2013). Translation and validation of the Ten-Item-Personality Inventory into Spanish and Catalan. Aloma: Revista de Psicologia, Ciències de L'educació I de L'esport Blanquerna, (31 (2)), 85-97.

Roberts, B. W., Walton, K. E., \& Viechtbauer, W. (2006). Patterns of mean-level change in personality traits across the life course: A meta-analysis of longitudinal studies. Psychological Bulletin, 132(1), 1-25. https://doi.org/10.1037/0033-2909.132.1.1

Robins, R. W., Tracy, J. L., Trzesniewski, K., Potter, J., \& Gosling, S. D. (2001). Personality correlates of self-esteem. Journal of Research in Personality, 35(4), 463-482. https://doi.org/10.1006/jrpe.2001.2324

Saucier, G. (1994). Mini-markers: A brief version of Goldberg's Unipolar Big-Five Markers. Journal of Personality Assessment, 63(3), 506-516. https://doi.org/10.1207/s15327752jpa6303_8

Schmitt, D. P., Realo, A., Voracek, M., \& Allik, J. (2008). Why can't a man be more like a woman? Sex differences in Big Five personality traits across 55 cultures. Journal of Personality and Social Psychology, 94(1), 168-182. https://doi.org/10.1037/0022-3514.94.1.168

Schumacker, R. E., \& Lomax, R. G. (2010). A beginner's guide to structural equation modeling (3rd ed). New York: Routledge.

Soto, C. J., John, O. P., Gosling, S. D., \& Potter, J. (2011). Age differences in personality traits from 10 to 65: Big Five domains and facets in a large cross-sectional sample. Journal of Personality and Social Psychology, 100(2), 330-348. https://doi.org/10.1037/a0021717

Steel, P., Schmidt, J., \& Shultz, J. (2008). Refining the relationship between personality and subjective well-being. Psychological Bulletin, 134(1), 138-161. https://doi.org/10.1037/0033-2909.134.1.138

Storme, M., Tavani, J.-L., \& Myszkowski, N. (2016). Psychometric properties of the French Ten-Item Personality Inventory (TIPI). Journal of Individual Differences, 37(2), 81-87. https://doi.org/10.1027/1614-0001/a000204

Tanksale, D. (2015). Big Five personality traits: Are they really important for the subjective well-being of Indians? Personality and subjective well-being. International Journal of Psychology, 50(1), 64-69. https://doi.org/10.1002/ijop.12060

Vorkapic, S. T. (2016). Ten item personality inventory: A validation study on a Croatian adult sample. The European Proceedings of Social and Behavioural Science (pp.192-202). https://doi.org/10.15405/epsbs.2016.05.20

Watson, D., Clark, L. A., \& Tellegen, A. (1988). Development and validation of brief measures of positive and negative affect: The PANAS scales. Journal of Personality and Social Psychology, 54(6), 1063-1070.

Woods, S. A., \& Hampson, S. E. (2005). Measuring the Big Five with single items using a bipolar response scale. European Journal of Personality, 19(5), 373-390. https://doi.org/10.1002/per.542 
Akhtar, H. 